\title{
Research on the Promotion Strategy of Enterprise Core Competitiveness Based on Human Capital Integration
}

\author{
Ma Zhongliang \\ Hainan College of Vocation \& Technique, Haikou, China
}

Keywords: human resources; core competitiveness; strategy

\begin{abstract}
The current stage is the era of knowledge economy. If an enterprise wants to grow, it must have its own core advantages. The essence of competition among enterprises is the competition of technical talents. Only by strengthening the absorption and management of talents can companies enhance their competitiveness. The improvement of the enterprise in the recruitment, training will also affect the talents system of the company and will have a certain impact on the competitiveness of the company. Based on the perspective of human capital, this paper analyzes the deep connotation between human capital and the competitiveness of enterprises, and provides corresponding strategies for improving the core competitiveness of enterprises according to the current situation of talents management in enterprises.
\end{abstract}

\section{Introduction}

The core competitiveness of an enterprise is a concentrated manifestation of the enterprise's competition and is the key to winning the competition among enterprises. There is a deep connection between the integration of human capital and the competitiveness of enterprises. Only by strengthening the management of enterprise talents can we fundamentally improve the competitiveness of enterprises.

\section{Human Capital and the Core Competitiveness of Enterprises}

\subsection{Human capital}

The theory of human capital considers that human capital refers to the knowledge and skills that workers have and the labor ability they exhibit. Human capital is flexible, and this kind of capital can be developed. Compared with physical capital, human capital has a greater effect on the development of enterprises. Human resources are the foundation of human capital and also potential human capital. Human capital can be owned by nature or acquired through study. Enterprises should pay attention to the production of acquired human capital. Enterprises can create human capital artificially according to their own development needs to enhance their internal human capital storage. The ways companies upgrade their human capital are also varied. They can recruit talented individuals or train the employees to upgrade their professional skills and literacy. While cultivating human capital, companies will also have a certain cost to pay. Therefore, companies must pay attention to the management of the company's human resources according to their own development status to enhance the company's core competitiveness ${ }^{[1]}$.

\subsection{The core competitiveness of enterprises}

The company's core competitiveness provides a steady stream of advantages in the process of corporate competition. The core competitiveness of an enterprise refers to the collective knowledge in the organization, which integrates various resources through coordinating the production skills in the enterprise. Just like a big tree, the trunk and main branches represent the company's core products, the fruit represents the enterprise's final products, the root represents the company's core competitiveness. The core competitiveness is very important to the development and competition of the enterprise. And enterprises must pay sufficient attention to this. 


\subsection{The connection between the two}

If enterprises want to gain a firm foothold in the market competition and achieve the final victory, they must make full use of the company's internal good resources and constantly seek the help of external resources. Through the optimal allocation of these resources to provide consumers with satisfactory products or services according to the specific conditions of the market. Enterprises should flexibly use their own knowledge and skills, and exert their internal cultural influence and management level to build their core competitiveness. Human capital is a manifestation of the knowledge and skills of employees, and is a basic component of building a company's core competitiveness. If enterprises can reasonably use internal human capital resources, they will be able to enhance their vitality. In the new market environment, human capital is a powerful driving force for enhancing the competitiveness of enterprises and ensuring their competitive advantages. Enterprises must recognize the importance of human capital and pay attention to internal human capital construction.

Human capital and enterprise characteristics have similarities and play a decisive role in the formation of a company's core competitiveness. Both are valuable and unique, and they cannot be replaced or imitated. The value of human capital is expressed in that employees within the enterprise have realized innovation and completed the organizational goals in their work by using the knowledge and skills they have learned, providing satisfactory service for the consumers and adding advantages to the competition of the enterprises. The human capital of enterprises is often scarce and cannot be duplicated. Therefore, human capital is also indispensable. The company develops and expands limited human capital through scientific methods, forming its own unique advantages $^{[2]}$.

\section{The Deficiencies of Human Capital Management in Enterprises}

The enterprise has achieved certain results in human resource management, established a relatively complete system of employment and selection of talents, and promoted communication among employees. However, there are still some deficiencies in the human resources management of the company, which will affect the human capital management of the company.

\subsection{Recruitment}

The company expands its internal employees through recruitment, adding talents to the company. Recruitment is very critical and is the first step for companies to introduce talents. If the overall quality of the recruited staff is low and does not meet the requirements of the company's development, it may increase the company's cost expenses, such as training fees and management fees. Some current enterprises lack a strict system in the recruitment process, and the recruitment process is incomplete, which is detrimental to the selection of enterprise talents. If an enterprise wants to select talents better from recruitment, it must improve relevant systems and strictly follow the process $^{[3]}$.

\subsection{Serious brain drain}

The company's human resources are constantly flowing, which also has a greater impact on human capital. The brain drain will directly lead to the lack of talented people in the enterprise and damage the interests of the company. If an enterprise wants to maintain its own competitiveness, it must strengthen the management of talents to prevent the loss of talents. The causes of brain drain are various, and may be due to poor work environment is harm to the body, the imperfect corporate promotion system, the lack of promotion space, the poor working atmosphere and disharmonious employees. If an enterprise wants to retain its talents fundamentally, it must strengthen its internal overall construction and increase the overall satisfaction of employees.

\subsection{The incentive system is not perfect.}

The imperfection of the enterprise incentive system will affect the enthusiasm of employees. Employees usually have the desire to obtain wealth and rewards. Enterprises must seize this upward 
mobility of employees, then improve the corresponding incentive system to promote employees continuous learning to obtain rewards for their applications through their own efforts. Some companies' incentive systems are incomplete and have an impact on employees' enthusiasm for work. Employees have no motivation at work and cannot do their best. Enterprises should be good at mobilizing the potential of employees, setting tasks and challenges for them, so as to enhance their enthusiasm and increase vitality for enterprises ${ }^{[4]}$.

\subsection{The training system is incomplete}

In the process of human capital formation in enterprises, training is critical. People can only become talented by continuous learning. Through internal learning, employees of an enterprise are able to master knowledge and skills, improve their own technical means, and strengthen their knowledge structure. Some current enterprises do not have sufficient training for employees because of the limitation of scale and funds, and therefore employees are not able to progress very well and it is not conducive to the formation of human capital in enterprises ${ }^{[5]}$.

\section{The Strategy of Improving the Core Competitiveness of Enterprises}

\subsection{Clear the needs and make a reasonable choice.}

To cultivate human capital in enterprises, we must first understand our own needs. Combined with the actual development of ourselves to enhance the ability of identifying human capital. Enterprises should verify the status of their own human capital and evaluate their value. Through the analysis of the human capital problem, the type of talents needed by the enterprise is clearly defined. It is more directional to cultivate human capital by targeted selection and training. Enterprises must also correctly identify their own core competitiveness. Enterprises should analyze their own characteristics, identify core advantages, and point out the direction for training human capital $^{[6]}$. Enterprises should become more targeted in the recruiting and training process to improve the efficiency of human capital development.

\subsection{Strengthen management and improve culture}

If an enterprise wants to enhance its core competitiveness, it must first pay attention to human resources management. Many companies have too much dependence on talents. Once these talents leave for a certain reason, they will have a greater impact on the company. Human capital can't be concentrated too much on a certain number of people. This poses a potential threat to the stability of the company. Human resources are very necessary for the formation of human capital. Enterprises must set up relevant human resources departments and improve corresponding human resources management systems to improve the efficiency of human resources management. Enterprises should spread the skills possessed by some individuals and let more people master them, which can reduce the dependence on certain people. Second, companies must create a good cultural atmosphere. Corporate culture is the soul of an enterprise and can have a subtle influence on employees. Excellent corporate culture can arouse the resonance of employees and attract talents. Corporate culture can enhance the feelings and cohesion among employees, so that all staff can unite and help each other and learn from each other.

\subsection{Build an exchange learning platform}

The formation of enterprise human capital depends on internal communication and knowledge sharing. It is necessary for companies to improve their internal information platform and enhance communication among employees. Employees can share knowledge on the platform and promote common progress. Employees in the company can enhance their knowledge and enhance their creativity through exchanges on the platform. It can also help them form a sense of competition and enhance their enthusiasm. The establishment of a learning platform can achieve the conversion of human capital between employees and organizations, promote collective progress, and enhance the company's core competitiveness. 


\subsection{Improve the restraint and incentive mechanism}

Human capital is different from material capital. The controller of human capital is the employee itself. Therefore, the size of this kind of capital output is affected by employees. Enterprises should strengthen the management of human capital and increase the utilization of human capital. Enterprises can improve the internal restraint and incentive system to promote the output of human capital and ensure the stability of human capital. Through the contract and the restraint system, the employees and the enterprise have realized the binding and signed a long-term contract, which can enhance their sense of responsibility and provide more contributions for the enterprise. Incentive systems can inspire their potential for hard work and make them more diligent in achieving their goals. The incentive system is not only for the individual's performance, but also related to the team's performance. This can promote employees to share with each other at work and promote common progress $\left.{ }^{[7]}\right]$. Enterprises must combine specific conditions when restraining and inspiring, and must not harm the employees' own interests.

\subsection{Increase the training intensity}

Corporate human capital relies on training, training can enhance the employees' knowledge and skills, and then enhance their core competitiveness. In modern society, the replacement of knowledge is very fast. If employees want to ensure lasting competitiveness, they must continue to learn. Enterprises should increase investment in employee training, improve internal training institutions, or invite outstanding external trainers to improve employee's skills. Enterprise training should focus on general employees' professional skills and culture, and it should be carried out in all directions and at various levels. Through training, employees can fully understand the company's culture, knowledge and skills, which enhance employees' love of the company, and promote the formation of human capital. The company also needs to improve its internal learning mechanism, establish employees' awareness of continuous learning, enable them to learn at work, and enhance their knowledge accumulation. In short, training can meet the needs of human capital of enterprises to a large extent and enhance the company's core competitiveness.

In summary, there are many links between the core competitiveness of a company and human capital. The competitive advantage of the enterprise lies in the core competitiveness, and the human capital of the enterprise is the key to the core competitiveness. If an enterprise wants to succeed in a fierce market, it must strengthen the construction of human capital and train more talents. From the perspective of human capital, if companies want to improve their core competitiveness, they must raise awareness of talent cultivation, increase training, improve the corresponding incentive system, and create a good corporate culture. In this way, they can guarantee the stability of human capital in all aspects and enhance the company's core competitiveness.

\section{References}

[1] Peng Song. Research on Human Resource Management Innovation Based on Cultivation of Enterprise's Core Competence [J]. Chemical Enterprise Management, 2018(12):3.

[2] Jianyong Chen. Constructing the Core Competence of State-owned Enterprises Based on Human Capital [J]. Market Modernization, 2017(16):74-75.

[3] Mengxue Jiao. Research on the Core Competence and Management System of Traditional Craft Enterprises [D]. Henan University, 2017.

[4] Yan Yan. Research on Evaluation of Core Competence of Construction Enterprises Based on Collaborative Innovation Network [D]. Hebei University of Engineering, 2017.

[5] Nina Zhang. Research on the Influence of Entrepreneur Human Capital on the Performance of Listed Companies [D].Yunnan University of Finance and Economics, 2017.

[6] Rui Qiu.The Effect of Enterprise Human Capital on Technological Innovation [J].CO-Operative Economy \& Science, 2017(04):94-95.

[7] Hui Xin. Analysis and Research on Human Resource Development Management and Enterprise Core Competence [J]. Modern Economic Information, 2017(02):77-78. 